\title{
Is the Use of Road Salt and Chemical Deicers Worth the Costs? A Call for Environmentally Sustainable Winter Road Operations
}

\author{
David M. Parker \\ Saint Xavier University \\ Tatiana C. Tatum \\ Saint Xavier University
}

The use of road salt and chemical deicers to control the accumulation of snow and ice on paved transportation surfaces has increased significantly over the decades. Estimates indicate that, each year, 60 million metric tons of salt alone is used globally for deicing. Deicing roadways and parking areas does provide an important service. It helps keep roads and parking areas navigable during snow and ice storms, reduces accidents and injuries and mitigates potentially significant economic losses to local, state, and regional economies due to closed roadways. But benefits do not come without fiscal and environmental costs. Extensive reliance on salts and harmful chemicals calls for the development and wide-spread use of environmentally sustainable and economically feasible alternatives.

Keywords: sustainability, deicers, road salt, environmental mitigation, 'deicing alternatives

\section{INTRODUCTION}

Each and every winter season large quantities of snow and ice control products are applied on paved surfaces as part of snow and ice removal efforts to ensure public safety and transportation (Sajid, et al., 2020; National Academy of Sciences, Foreword, 2007). The environmental impact resulting from the use of these products has been questioned for decades by environmental and regulatory agencies (National Academy of Sciences, Foreword, 2007). Transportation agencies have been encouraged to seek out and use "environmentally friendly" or less toxic alternatives. Yet no commonly accepted guidance for determining which products are acceptable has been issued.

In considering standard and alternative methods of deicing, it is important to consider both fiscal and ecotoxicological impacts. We look here at four chemical deicers: sodium chloride, magnesium chloride, calcium magnesium acetate, and potassium chloride. We then highlight several alternative deicers: beet juice, carbohydrate enhanced chemicals, cheese and dairy brines, garlic salt, grass/kitchen waste, and pickle brine. We conclude with an overview of significant contributions of technological advances.

Pricing varies greatly for the chemical deicers. Sodium chloride (i.e., salt) is the least expensive of the four listed, but also comes with significantly adverse consequences. Economic impacts of using road salt for snow and ice control include corrosion damage to roads, bridges, parking garages, and underground utilities, as well as the costs of undertaking measures to protect against and minimize the effects of corrosion (National Academy of Sciences, Chapter 10, 2007). 
Corrosion caused by road salt also negatively impacts motor vehicles, especially brake linings, frames, and bumpers. Taking into account these considerations, the costs of using road salt becomes considerably greater. Research indicates that the use of road salt can have devastating impacts on roads, bridges, buildings, and the environment (Russell, 2017). Additionally, some researchers have found that environmental pollution caused by increases in salinity may have broader effects on humans than previously understood (Hurley, 2018). While magnesium chloride has the least environmental and corrosive impact, all four have chemical limitations and result in negative ecotoxicological impacts, including toxic runoff and corrosion. These deicers contain highly soluble and extremely mobile chloride. Chlorides are not naturally broken down, metabolized, taken up, or removed from the environment, making them exceptionally toxic to all life. With respect to the environmental impact of road salt use, this hazardous substance is entering the environment in quantities that may pose immediate or long-term environmental risks. Elevated concentrations of chloride salts may cause adverse effects to wildlife (including aquatic life), plants, water and soil (Jones, et al., 2017).

Over the past several decades, significant advances in winter maintenance technology and practice have been made. Low chloride alternatives to road salt have been developed. Improved equipment and application techniques have been employed. And technology advances enable for greater ability to accurately monitor weather and pavement conditions. Winter maintenance practitioners possess many tools to more safely and effectively control snow and ice using less road salt. (Environment Canada, 2004; Environment Canada, 2012).

But despite the cheap economic price of road salt and technological advances, the accumulated and large-spread effects of its widespread use will most certainly reach critical mass. Studies, reports, and anecdotal observations have demonstrated that the environmental impact of road salt, for example, on wildlife, water, soil and plants, can be so distressing that it might be added to a list of highly toxic substances (Philip, 2018). More and more focus is, and should continue to be, given to finding economically affordable and environmentally sustainable alternatives to use for ice and snow control on roads.

\section{ENVIRONMENTALLY SUSTAINABLE ALTERNATIVES TO SODIUM CHLORIDE}

In light of costs and environmental concerns, state agencies continue to cut back on road salt usage for snow and ice on roadways by spraying liquid salt brine - most commonly a mixture of 23 percent salt and 77 percent water - rather than spreading road salt alone. It has been estimated that this approach cuts salt use by at least 30 percent. Treating roads with the brine helps the salt stick, and also creates a barrier between the road and the snow and ice to prevent them from bonding to the pavement (Fifield, 2017).

A small, but growing, number of communities have been testing more environmentally friendly alternatives to control ice and snow. And it awaits to be seen if some or all of these alternatives have the potential to become more widely used (Philip, 2018). And while traditional payment deicers, such as road salt, continue to be widely used, research on alternatives continues, for example, current studies are being conducted on the use of environmentally safe and low-cost corn-derived polyols to add to traditional payment deicers to reduce the corrosivity (Sajid, et al., 2020).

Here is a look at alternatives that local and state officials are using or have used in place of sodium chloride to support sustainable winter road operations.

\section{Beet Juice/Beet Brine}

Municipalities across Canada and the United States have sprayed beet juice on roads before snow arrives or have mixed the juice with salt and spread the mixture on roadways to make de-icing processes more effective. The most common approach has been to mix sugar beet molasses, a waste by-product of beet sugar refining, with salt solutions. Beet brine produces the same ice-melting effects as higher concentrations of salt alone, and the brine has a lower freezing point than a salt, effective at temperatures above $-22^{\circ} \mathrm{F} /-30^{\circ} \mathrm{C}$, whereas salt is only effective until about $-13^{\circ} \mathrm{F} /-25^{\circ} \mathrm{C}$. This approach can decrease the amount of the salt typically used or wholly eliminate its use when the mixture is $100 \%$ beet brine. When used with a salt, the brine helps it bond to the surface of the road where its effects are maximized. The 
brine, however, can be up to four times more expensive to use than typical salt (Transportation Gazette, 2019).

As to environmental impact, the brine can leak into streams or other small waterways, resulting in concern for biochemical oxygen demand. The sugar can attract bacteria that suck up much or all of the dissolved oxygen in the water on which aquatic animals and organisms rely (Silverman, 2014). Because it has not been used on a mass scale, more research is needed to investigate the negative effects of the mixture. Beet brine does not have the corrosive and damaging affect that sodium chloride has. Currently, the barrier is economic cost (Transportation Gazette, 2019). Yet while economically more expensive (about four times more expensive than salt), the negative external costs of using beet brine are not passed onto the population and the environment. The opposite applies to sodium chloride use. Further research should be conducted on the use of the brine for snow and ice control along with attendant environmental effects, including viewing its use through a cost benefit lens (Transportation Gazette, 2019).

\section{Cheese and Dairy Brines}

Cheese brine - a liquid byproduct of making mozzarella and provolone - has been used to reduce road salt usage for de-icing roads. In Wisconsin, a massive producer of dairy products with plenty of cheese brine byproduct available, local governments have teamed up with dairy companies to use liquid cheese brine to combat ice road conditions. For example, one rural Wisconsin county, Polk County, has in the past used tens of thousands of gallons of the brine each year along with road salt. They obtained the brine from a local dairy and cheese producer, which itself thus saved money in not having to pay to have the brine removed as a waste product. The mixture works more effectively at colder temperatures than regular road salt alone, and that the brine helps salt stick to the road (rather than bouncing off) and helps speed melting. As a result, the county has been able to use significantly less salt and save money. And county officials have reported that there is no residue or any problems associated with their use of the brine for de-icing roads (NPR, 2014; Fifield, 2017; Stotterud \& Reitan, 1993; Yang, Zhu, Lewis, Tang, 1992).

\section{Garlic Salt}

Many communities use sea salt for snow and ice control on streets. But a mixture of sea salt or table salt and dried garlic, i.e., garlic salt, is traditionally associated with culinary uses. But in late 2008 when Tone's Spices found itself with a huge amount of excess and outdated garlic salt at its large spice production facility, the corporation donated 9 tons of the substance to the local community of Ankeny, Iowa (a suburb of Des Moines). City administrators accepted and picked up the donation, and combined the donated garlic salt with road salt. The city subsequently used the salt mixture to de-ice its 400 miles of city roads after a winter storm had dumped 4 inches of snow on the community. Community members apparently had mixed reactions to the garlic aroma in the air, but most of this salt mixture supply was used quickly as the city put down between 100 and 150 tons of salt after snow storm (NPR, 2008; Russel, 2017).

\section{Biomass Sources (e.g., Grass, Woody Residues, and Kitchen Waste)}

Researchers are experimenting with biomass sources, such as grass and kitchen waste, to create a "green" de-icing salt. Specifically, the biomass is used to produce calcium magnesium acetate, which is an organic salt that is a powerful but currently costly de-icer. Scientists are seeking to develop this "green salt" on a large scale (Russel, 2017; Trantolo, Gresser, Augenstein, Wise, 1990; Wise \& Augenstein, 1988). Scientists at private firms in the United States are working to develop nontoxic deicing/anti-icing fluids that include some form of a biobased freezing point depressant (United States Patent 7270767; Google Patents (CA2503859C)).

Researchers in Alaska have been working to develop innovative anti-icing formulations using beet sugar refining byproducts, glycerol, and other biobased additives. The research team has developed, for example, a process to chemically and biologically degrade flower waste into a mixture of molecules that can significantly reduce the corrosiveness of salt brine to carbon steel. The flower waste used was peony leaves and stalks, which are available in large quantities from the Palouse region, which is a distinct 
geographic region of the northwestern United States, encompassing parts of north central Idaho, southeastern Washington, and parts of northeast Oregon (U.S. Department of Transportation, 2015).

Similarly, researchers are also considering the possible use of liquid wastes as well as leftover corn, barley, and rye from distilleries that make vodka, rum, or bourbon or other whiskeys to develop costeffective alternatives to high-cost commercial products currently available to enhance the anti-icing/deicing performance of salt brine (Shi \& Jungwirth, 2018). Researchers note that additional studies are necessary to establish application rate guidelines and to determine the effectiveness of any new products. Moreover, researchers note that further research is necessary to ensure that any newly-developed products do not have significant adverse environmental impacts, for example, that they do not have high biochemical oxygen demand or chemical oxygen demand or pose a significant risk to aquatic life (Shi \& Jungwirth, 2018).

\section{Pickle Brine}

Pickle brine is effective, costs significantly less, and is better for the environment than salt. The salty, green liquid, which works like regular salt water, melts snow as efficiently as salt. The brine can melt ice at temperatures as low as $-6^{\circ} \mathrm{F}\left(-21^{\circ} \mathrm{C}\right)$, which makes it similar to traditional rock salt. And when concrete and paved surfaces are prewet with the brine, it prevents snow and ice from bonding with pavement and thus makes ice easier to remove. Based upon its effectiveness, some states, like New Jersey and Pennsylvania, have sprayed the brine on sidewalks and streets in order to reduce the usage of salt for deicing. The use of brine can reduce the amount of chloride released into the environment by 14 to 29 percent (Silverman, 2014).

The development of alternative anti-icing products that can be used on a wide-spread basis could generate significant cost savings for DOTs and other maintenance agencies, benefit travelers through improved safety and mobility, and better address environmental concerns. The development and use of alternative products could, for example, reduce damage to infrastructures and reduce harmful environmental impacts from winter roadway operations. Moreover, the development of biobased renewable additives could also add value to agricultural by-products and stimulate local economies (U.S. Department of Transportation, 2015).

\section{THE IMPORTANT CONTRIBUTION OF TECHNOLOGICAL ADVANCES}

\section{High-Tech Solutions to Snow and Ice Control}

Road salt, chemicals, and brines are not the only means to rid roadways of snow and ice. There are a number of other high-tech solutions. Municipalities and DOTs are using electronic spreading systems on their trucks to intelligently deliver just the right amount of salt to roads and parking lots. They are timing their salt applications better and using less salt overall. They are using technology to monitor weather conditions to decide whether and when to use salt or other deicers. And then there are ambitious, high-tech solutions like automated deicing systems and heated roads (Chen, $\mathrm{Su}, \mathrm{Ye} \& \mathrm{Fu}, 2018$; Fujimato, Saida \& Fukuhara, 2012; Lu, Xu, Bai, Liu \& Luo, 2017; Zhao \& Chen, 2008).

\section{CONCLUSION}

Road salt has been relied upon, for decades, to combat icy roads. Yet it and other conventional antiicing agents are not without shortfalls. The negative externalities of sodium chloride, and other substances, need to be studied to evaluate their true costs to society. These traditionally used substances are plagued by growing concerns over their corrosion effect on metals, destructive impact on concrete and asphalt, and toxicity to aquatic environments and resources. And while application techniques and storage methods have changed to increase effectiveness and minimize negative impacts, the question remains: Are there other ways to keep transportation surfaces safe to use during the winter that better protect our infrastructure and, more importantly, the environment? 
It is important that we continue to develop and deploy environmentally-friendly and renewable antiicing formulations and products. This includes the continued and expanded use of locally-sourced "green" additives such as environmentally-friendly biobased materials. It also includes research to identify how to convert low-toxicity industrial byproducts into renewable additives for "greener" anti-icing formulations that pose minimal toxicity to the environment, e.g., low nitrogen, phosphorus, and heavy metal contents

All deicing methods have fiscal and environmental costs. De-icing chemicals and road salt additives as well as alternatives currently range in price from inexpensive to prohibitively expensive. Some, or all to a degree, alter ecosystem function and services. Further research is needed to determine their impacts on higher trophic levels. Comprehensive study of additives and alternatives must be conducted before any wide-scale use is implemented. Existing evidence indicates, however, that the environmental impacts of the alternative methods identified are far less significant than the standard methods of deicing. Yet fiscal costs are much more significant if additives and alternate methods are introduced at an industrial scale. But it is clear that there is ample opportunity and motive to find alternatives to deicers currently in wide-spread use.

For example, large scale operations producing vast quantities of biomass as waste might increase their overall profits if they support the development and production of deicers with that waste, which could be sold as environmentally-friendly alternatives to destructive salts.

\section{REFERENCES}

Chen, F., Su, X., Ye, Q., \& Fu, J. (2018). Experimental Investigation of Concrete Runway Snow Melting Utilizing Heat Pipe Technology. The Scientific World Journal, pp. 1-6. Retrieved January 31, 2021, from https://www.hindawi.com/journals/tswj/2018/4343167/

Environment Canada. (2004). Best Management Practices for Salt Use on Private Roads, Parking Lots and Sidewalks. Retrieved January 29, 2021, from https://sustainabletechnologies.ca/home/urbanrunoff-green-infrastructure/pollution-prevention/road-salt-management/

Environment Canada. (2012). Five-year Review of Progress: Code of Practice for the Environmental Management of Road Salts. Retrieved January 29, 2021, from http://publications.gc.ca/collections/collection_2012/ec/En14-54-2012-eng.pdf

Fifield, J. (2017). Using Cheese, Molasses Brine to Treat Roads with Less Salt. Retrieved January 29 , 2021, from https://www.pewtrusts.org/en/research-and-analysis/blogs/stateline/2017/05/01/usingcheese-molasses-brine-to-treat-roads-with-less-salt

Fujimato, A., Saida, A., \& Fukuhara, T. (2012). A new approach to modeling vehicle-induced heat and its thermal effects on road surface temperature. Journal of Applied Meteorology and Climatology, 51(11), 1980-1993.

Google Patents (CA2503859C, Canada). (n.d.). Biobased Deicing/Anti-icing Fluids. Retrieved January 30, 2021, from https://patents.google.com/patent/CA2503859C/en

Hurley, J. (2018). Can road salt and other [pollutants] disrupt our circadian rhythms? Scientific American, THE CONVERSATION US, Biology. Retrieved January 29, 2021, from https://www.scientificamerican.com/article/can-road-salt-and-other-pollutants-disrupt-ourcircadian-rhythms/

Jones, D.K., Mattes, B.M., \& Hintz, W.D. (2017). Investigation of Road Salts and Biotic Stressors on Freshwater Wetland Communities. Environmental Pollution, 221, 159-167.

Lu, S., Xu, J., Bai, E., Liu, J., \& Luo, X. (2017). Investigating Microwave Deicing Efficiency in Concrete Pavement. RSC Advances, 7(15), 9152-9159.

National Academy of Sciences. (2007). Foreword: Guidelines for the Selection of Snow and Ice Control Materials to Mitigate Environmental Impacts. National Cooperative Highway Research Program, NCHRP Report 577. Retrieved January 29, 2021, from https://www.nap.edu/catalog/23178/guidelines-for-the-selection-of-snow-and-ice-controlmaterials-to-mitigate-environmental-impacts

National Academy of Sciences. (2007). Chapter 10: Effect of Snow and Ice Control Material on Reinforcing Steel Corrosion. National Cooperative Highway Research Program, NCHRP Report 
577, 127-133. Retrieved January 29, 2021, from https://www.nap.edu/catalog/23178/guidelinesfor-the-selection-of-snow-and-ice-control-materials-to-mitigate-environmental-impacts

NPR. (2014). Cheese To the Rescue: Surprising Spray Melts Road Ice. Retrieved January 29, 2021, from https://www.npr.org/sections/thetwo-way/2014/01/21/264562529/cheese-to-the-rescuesurprising-spray-melts-road-ice

NPR. (2008). Facing Ice, Snow, Iowa Town Looks To . . Garlic Salt. Retrieved January 30, 2021, from https://www.npr.org/templates/story/story.php?storyId=98529510

Philip, L. (2018). Alternative Ways to Melt Ice: Pass On The Salt And Pick Up The Beet. Soil Advocates. Retrieved January 29, 2021, from https://www.soiladvocates.ca/alternative-ways-to-melt-ice/

Russel, A. (2017). Why Do We Still Use Road Salt and What Are the Alternatives? Global News. Retrieved January 30, 2021, from https://globalnews.ca/news/3174300/why-do-we-still-use-roadsalt-and-what-are-the-alternatives/

Sajid, H.U., Kiran, R., Qi, X., Bajwa, D.S., Battocchi, D. (2020). Employing corn derived products to reduce the corrosivity of pavement deicing materials. Construction and Building Materials, 263, 120662. Retrieved January 29, 2021, from https://doi.org/10.1016/j.conbuildmat.2020.120662

Shi, X., \& Jungwirth, S. (2018). The Search for "Greener" Materials for Winter Road Maintenance Operations. In X. Shi \& L. Fu (Eds.), Sustainable Winter Road Operations (pp. 378-422, at 396). New Jersey: John Wiley \& Sons Ltd.

Silverman, R. (2014). Why Pickle Brine is a Secret Weapon Against Ice. National Geographic. Retrieved January 29, 2021, from https://www.nationalgeographic.com/news/2014/2/140204-melt-snowice-salt-beet-juice-pickle-brine/

Stotterud, R., \& Reitan, K.M. (1993). Deicing of Roads in Norway with Brine Transportation Research Record (1387, 23-28). Washington, DC: National Academy Press.

Transportation Gazette. (2019). Road Salt vs. Beet Brine: De-Icing in Canadian Cities. Retrieved January 29, 2021, from https://www.thetransportationgazette.com/blog/road-salt-vs-beet-brine-de-icingin-canadian-cities

Trantolo, D.J., Gresser, J.D., Augenstein, D.C., \& Wise, D.L. (1990). The Feasibility of a Residue Biomass Bioconversion Process to Prepare Calcium Magnesium Acetate Deicing Salt. Resources, Conservation and Recycling, 4(3), 215-232.

United States Patent 7270767. (n.d.). Environmentally Friendly De-icer and Anti-icer Compositions. Retrieved January 30, 2021, from http://www.freepatentsonline.com/7270767.html

U.S. Department of Transportation, Office of Research, Development and Technology. (2015). Bio-Based Renewable Additives for Sustainable Roadway Snow and Ice Control Operations. Retrieved January 30, 2021, from https://www.transportation.gov/utc/bio-based-renewable-additivessustainable-roadway-snow-and-ice-control-operations

Wang, H., Zhao, J., \& Chen, Z. (2008). Experimental Investigation of Ice and Snow Melting Process on Pavement Utilizing Geothermal Tail Water. Energy Conversion and Management, 49(6), 15381546.

Wise, D.L., \& Augenstein, D. (1988). An Evaluation of the Bioconversion of Woody Biomass to Calcium Acetate Deicing Salt. Solar Energy, 41(5), 453-463.

Yang, S-T., Zhu, H., Lewis, V.P., \& Tang, I-C. (1992). Calcium Magnesium Acetate (CMA) Production from Whey Permeate: Process and Economic Analysis. Resources, Conservation and Recycling, 7(1-3), 181-200. 